\title{
The study on outdoor space type of kindergarten based on the architectural typology with BUA kindergarten as an example
}

\author{
Jing Wei Zhang ${ }^{1, \text { a }}$, Sheng Lu ${ }^{2, b}$ \\ ${ }^{1}$ Beijing University Of Agriculture, China \\ ${ }^{2}$ Beijing University Of Agriculture, China \\ a15210930189@163.com, 'is@bua.edu.cn
}

\begin{abstract}
Keywords: architectural typology, outdoor spaces type, BUA kindergarten.
Abstract. With constantly improvement of child education idea, the construction of the outdoor space environment for the kindergarten and the use of it are attracting more and more attention. Kindergarten work procedures which specify "children's outdoor activities of time (including outdoor sports time) shall not be less than 2 hours a day, boarding kindergarten shall not be less than 3 hours", which make outdoor space become more important carrier in kindergarten daily teaching process. Based on humanism in the architecture field (that is, the demand of people is the most important characteristics of space) for the type of interior space studies has certain reference significance for outdoor space. So this article applies the architectural space research methods of typology study in kindergarten outdoor space type study. On the basis of restricted factors such as the limited fund, land, education system and so on, considering the demand of children's outdoor activities, according different functions, the kindergarten outdoor space is divided into learning space, games, space and physical space, advertising space and experience of space.
\end{abstract}

\section{The definition and significance}

Typology. In the powerful concise British encyclopedia, Typology is defined as" a method of packet classification system, each component of type rely on assumption of various special attributes to identify. These properties are mutually exclusive to each other and set up everything again. This classification method for its limited relationship among the various phenomena is helpful to argumentation and explore "[1]. Meanwhile, in Andreas Faludi's planning theory, Typology is defined as a summary of phenomenon and abstracts extracted to explain events, but also is a theory that can clearly illustrate the mode of relationship among various phenomenon [2]. It is a research method or systematic classification for those that have a common characteristic or feature type. And typological research methods actually try to explore the deep inner structure through the phenomena.

Taxonomy. Taxonomy is used for the classification of natural science, which have the difference and connection with Typology [5]. Taxonomy focus on natural attributes, however typology can be used to study the variabilities and transitional problems, which have inheriting properties, Generic changes are more subtle, so the taxonomy for natural science is more difficult to meet those requirements.

Achitectural Typology. Architecture used to be classified by function, form, structure, regional classification, etc., so behavior in architecture should be rather than a taxonomy of typology rather than a taxonomy [4]. According to the definition of typology, treating a continuum system as a classified method applies on architecture, so the architecture typology produced. In addition to the historical description and scientific analysis, the most practical significance of architectural typology is attempt to find the general principles in buildings from a variety of arrangement in the past buildings. While the principles return to practice, there will be produced new forms to answer the new and promoting environments.

Landscape Typology. Architecture typology was applied to landscape architecture, classifying the space of the landscape architecture by the function, form, structure, elements and so on, so the landscape typology produces [5]. Space is a material existence form which is compared to time .outdoor is compared to the concept of indoor, so compared the internal space, the outdoor space 
should be a material existence form which is limited by the shape of the structure, plant shape contour and other hard materials. It has relativity and material, as well as the time transitivity. Based on the transmission properties of outdoor space, applying typology classification principle, this article classify the outdoor spaces of kindergarten by function to study specs classification.

The kindergarten. According to principle in our country "the kindergarten work regulations", it said that "the kindergarten is an organic part of basic education, which is preschool children care and education institution for more than three years of children, and also is the foundation stage of school education system.... children in kindergarten used to be at the age of 3 to 6 or 7."[6] In the Westerns, the commonly expression for this preschool institution are "kindergarten, infants' school, nursery school," which is to take care of $4 \sim 6$ years old preschool children. Therefore, children referred in this article are aged $3 \sim 6$ or 7 years old children.

Preschool. Preschool children referred to are those who don't reached the school age in law, According to "Law of Compulsory Education" in our country, it says that all children over the age of six should go to school for compulsory education, while it can be postponed to the age of seven when the local educational condition is poor .Preschool is preschool education institution for one year, which is the preparatory stage of school education. Preschool at present are set up at where preschool education is relatively underdeveloped (mainly in rural areas and small towns), which cannot popularize preschool education in three years ( $3 \sim 6$ years of early childhood education), and that is a kind of auxiliary and complementary for shortage of kindergarten, not higher than kindergarten education form. Therefore, $\mathrm{t}$ a significant difference between the kindergarten and preschool is the length is different, preschool for 1 year, kindergarten for three years.

Research objects. To sum up, the research objects of this paper is space outside the kindergarten which is education institution for the age 3 6 located in the city Compared to the children before the age of three ,children at the age stage $3 \sim 6$ greatly enhance the abilities of activity, games and communication ,meanwhile the form go to diversification. After 3 years old, the patience, the acceptance of delayed gratification, the disappointment and the tolerance of children enhance, and the dependence passively and negatively reduce, so it is a sign of maturity for children, game and communication can create a better growth environment for children. Thus the kindergarten outdoor environment construction should be paid more attention to the psychological needs of children so that build more suitable outdoor activity space for children.

L. collier treats city as a whole, and he was opposed to partition, he put forward in the rational building that cities have different hierarchy, and each level has its own system. Namely, every space should be a

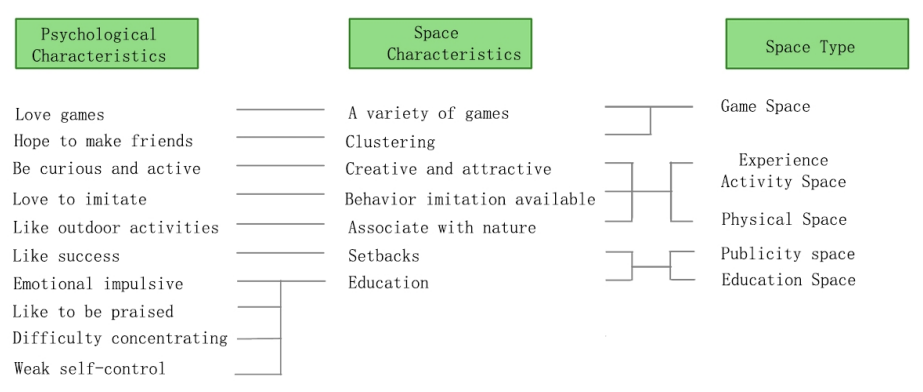
multi-level exhibiting different systems on different hierarchy. In the function level, the kindergarten outdoor space will have the different space types, and each space should be multi-function, rather than single[5]. And the functional partition in landscape is based on $2 \mathrm{~d}$ classification method, which is occupied by the bottom interface. However, space type which focus on space characteristics study is based on the three-dimensional. In this article, According to different space function of the kindergarten outdoor space, the kindergarten outdoor space is divided into education space, advertising space, physical exercise space, experience the practice space as shown in Fig1. 


\section{BUA kindergarten outdoor space type analysis}

Introduction. The old kindergarten was located in a small courtyard garden in Beijing University of agriculture campus before 2011, when it moved to the northwest of campus, and it is equipped with six classes for 3-6 years old children. Covering an area of $10092.54 \mathrm{~m}^{2}$ up from the original $2638.6 \mathrm{~m}^{2}$, the building construction area are also changed from the original $691 \mathrm{~m}^{2}$ to $3149.54 \mathrm{~m}^{2}$, and outdoor area has expanded from $1612.3 \mathrm{~m}^{2}$ to $3387 \mathrm{~m}^{2}$.Green area together are of $3556 \mathrm{~m}^{2}$. First-class quality of

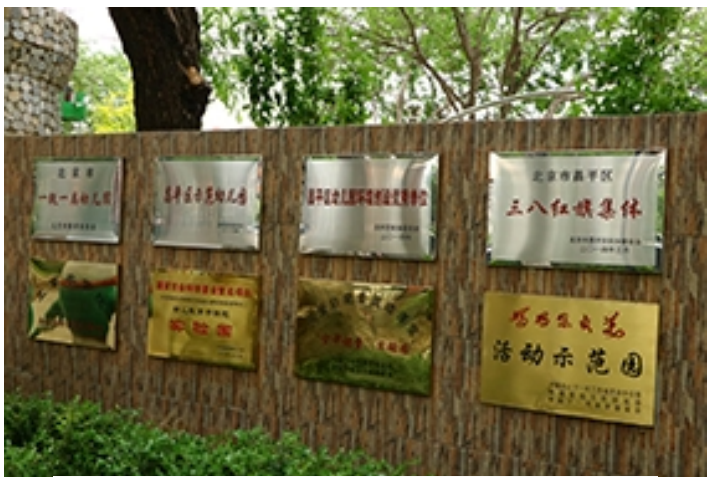

Fig2.BUA kindergarten social honor service and good reputation are widely recognized by the social, which is awarded "advanced unit" title for many times, is evaluated "the level of first class of kindergarten in Beijing in 2013 and" excellent unit in changing kindergarten environment "in 2014 as shown in fig2.

According to the requirements of children in outdoor space and relative regulatory requirements, the kindergarten creates a reasonable curriculum. outdoor activities can be divided into two periods, namely: the lesson hold time (9:40 to 10:30), outdoor free time in the afternoon (from 15:00 to 16:00)[8].In these two periods, guiding children do some outdoor activities. According to the above methods, As shouwn in 3,4BUA kindergarten outdoor space are divided into education space, game activity space, experience activity space, physical activity space and the promotion space.

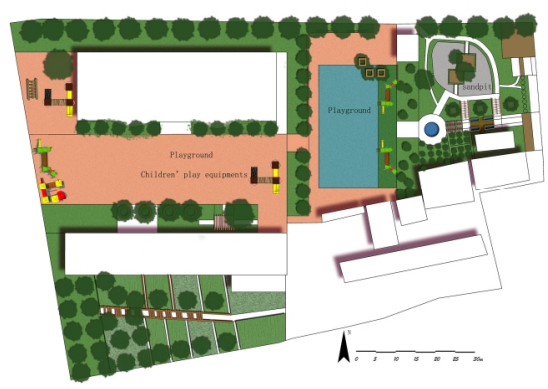

Fig3 BUA kindergarten Plan

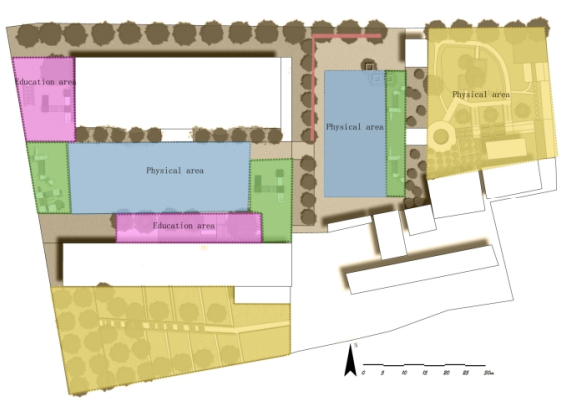

Fig4 function space plan

BUA kindergarten outdoor education space are mainly concentrated in the agricultural education, sports, environmental moral education and moral education, which take good advantage of the outdoors environment for children to guide education. Its distinctive outdoor farmer education courses enhance the effect of the environment of moral education and let children have a deeper understanding of the environment. However, there is no clear boundaries between game space and experience activity space. Experience activity space has more education factors and is creative, while game activity space is slightly mediocre. Game equipment is relatively traditional and lack of innovation. Introduce more game creative equipment, children may have more desire to play.

Education Space. Kindergarten is a preschool education institutions, so it must have the function of education. In the "modern Chinese dictionary", "education" is that "training new generation ready to engage in the whole process of social life", which means society guide people thought and behaviors in social life[8]. So education space should be a place guiding people to improve the knowledge and skills, influencing people's ideology and moral character. Education should include indoor education and outdoor education. The study object of this article is outdoor space, outdoor education space in BUA kindergarten are two main types, one type is surrounding the building, another is whole campus of BUA. 
Type one. space surrounding building, which back against the building for gathering the children, not only can take advantage of buildings to provide shadow for children, but also help kindergarten teachers' care. In fig 5 , teacher is teaching children about plants, and $t$

each them how to keep it in the pot, and children are listening carefully around the teacher sitting in chairs or small bench below the tree. Agricultural Education is characteristic in BUA kindergarten education system, it makes children gain a fundamental sense of agricultural production. More and more children in city are unable to distinguish one kind of grain from another. So based on

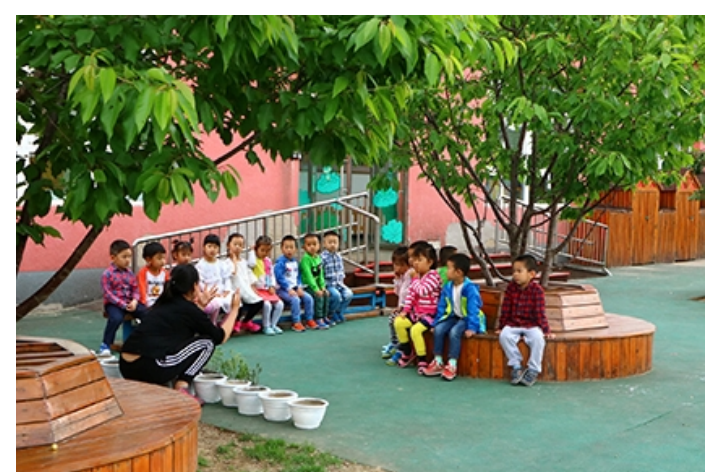

Fig5 children are studying plant the characteristic agroforestry of BUA, BUA kindergarten creates a unique agricultural education courses, which is to teach children to know some of the more widespread crops and cultivate the children some basic farming abilities in a natural environment.

Meanwhile, BUA kindergarten sets environment education courses for children, which is relatively lack of education for lots of kindergarten. Environment moral education is such a course that arouse children's preliminary consciousness of environment protection. By observing the surrounding environment, let children pay attention to the changes happen around environment, so that they have more intuitive experience about natural process. By building contact between children and nature, let children have more responsibility to cherish and protect environment, and it's important and necessary to cultivate from childhood. BUA kindergarten environment education space is combined with the experience activity space, and the external environment of BUA kindergarten, even urban environment.

Game Space. BUA kindergarten game equipment mainly are traditional instruments, which include with sliding type equipment such as slide for child to experiencing speed, exercising their courage; and balance type instrument such as seesaw, single-log bridge, the balance beam to exercise their balance and patience; and climbing instruments such as the drill pipe to training their power and flexible limbs[9]. BUA kindergarten take comprehensive advantage of above instrument creating a set of continuous activity content. It can save area for children to gain comprehensive training. Punctiform game-space above all together constitute a series of continuous linear space.

Game space is important not only based on the importance of the nature of children for loving games, but also as an important place for social activities. BUA kindergarten game space presents the characteristic as follows.

Borderline. BUA kindergarten game space show a feature of multipoint linear distribution. Each class in kindergarten has their own independent space, so there are lots of point space. The whole outdoor game equipment placed along the edge of buildings, which can attract children from indoor to outdoor for outdoor activities. Meanwhile equipment placed along the area, to expand the spaciousness for the greatest possible, to make more space for more centralized activities (setting- up exercises during the break, sports, flag-raising ceremony etc.).

Security. Security is an important principle in every design, Of course, kindergarten design should even more safety. EPVC (Ethylene Vinyl Acetate) are used in pavement and other hardscape in kindergarten. The entire area without sharp object threat the safety of children. Ensuring the security of children, the kindergarten leader believe that giving children some setback education in their growth is very necessary. They should know life isn't easy and the way is more of setback than smooth. But setback education is ignored by most kindergarten in our country. Games mixture with setback education is very important, because setback education in games can more easily accepted and understanding by children. "Combining education with recreation" is not only a principle in teaching, but also in this space design 
Clustering. According to "need hierarchy theory" of Maslow, followed by a lower level to higher level, human have physiological needs, safety needs, Love and belonging (social needs), esteem and self-actualization five kinds of demand. Compared with the mature self-psychological management of adults, human nature of children is more obvious. So the children's game of social space (game space) should be clustering for kids gathering. Each class in BUA kindergarten have their relatively independent space to ensure children' s basic gathering for social psychological needs. As for size of space, It should be decided by the number of children in a class. Generally speaking, it shouldn' $t$ be less than $60 \mathrm{~m}^{2}$, if area is big enough, $80 \mathrm{~m}^{2}$ is also allowed [10]. Too big independent space may cause teachers' blind area going against care, on the other hand, the independent space is too small to play appropriate game campaigns for too crowded children.

Experience Space. American writer Richard Louv put forward an amazing phenomenon in the article "Last Child in the Woods" that children are separate from natural. He defined this phenomenon as a "nature deficit disorder".[11] "child psychology" mentioned in his book thinks that playing alone, especially in early childhood, can be able to develop a kind of important way of management and self-control ability, They can be their own boss and be self-discipline, make their own decisions... independent play we say is refers to that when children is playing, there are no interference from their parents and machine... the best scenario is in the nature environment, letting children play in nature is the best among independent scenarios." Natural space is the key point in children's outdoor space construction.

BUA kindergarten blend natural into children' experience activities to create unique experiential space, which is the largest green clusters in kindergarten. Experience space includes two parts, one part is located in the eastern part of the kindergarten named career exploratory space for professional experience activities, the others are rural space for farming activities in the south of the kindergarten.

Exploratory space is rectangular and of about $1637 \mathrm{~m}^{2}$ with the distinctive fence enclosing a closed space alone. The construction has the same effect with Richard's theory. In terms of greening, greening reinforcement sealing effect created by fence. Arbor is plant in the middle of the area with shrubs and herbs around it for a transparent sight from middle to outside. The shadow of tall trees covers the whole space so that the whole area is in a natural environment. The career exploratory refers to that the area set up all kinds of professional experience space. There are fishing pond close to the main entrance, Children can play on the bridge, and armrest of $1 \mathrm{~m}$ is set for security principles. Besides, there is pictures and signs beside bridge listing method of fishing. Children can also experience the fun of being a fruit famer from watering fruit trees around to let them know that every single grain is the result of toil. Farm animals, such as sheep, ducks, etc., can also give children the basic environment education. There is a small restaurant in the north of the small zoo, children can open a restaurant as a cook, or be a guest sitting around a small glass table at tree-lined yard. Three small cane and table are placed on a wooden platform with sand surrounded to create a unique atmosphere. Children like climbing and jumping for the natural, so exploratory space are equipped with stakes to train leg skills, the balance beam, tire step which is the entity's tire in the center, and children can climb on a slightly undulating terrain.

Rural area is a rectangular covering an area of $1844 \mathrm{~m}^{2}$. Farming education is one of characteristics in BUA kindergarten. There was only one entrance to the area with cartoon modelling of fruits and vegetables to attract the attention of children. And this space is separated with fence from the university campus. The whole area is divided into the north and the south two parts by a long corridor, on which there are some picture about children activity. The northern regions are divided into a number of small rectangular vegetable gardens about $1.5 \mathrm{~m}$ long, $3 \mathrm{~m}$ wide with trellis above to plant some lianas. The south part is tree and grass interplanting, and most trees are fruit trees, herbs are vegetables. Each vegetable-beds is plant one type vegetables. The kindergarten teachers introduced that they will lead the children come here to do some seasonal farming activities, such as planting, weeding, 
watering. And these simple farming activities are like not only by children, but also appreciated by their parents, this is a great way for children to contact with nature and labor.

Physical Space. Physical exercise is an important part of the activities, but incorrect physical exercise may cause the damage to the body [12]. So one of the principle of construction is to try our best to avoid the body damage when they exercise to ensure their health in growth. BUA Kindergarten main sports venues are two large playground located in the middle of the building. An iron gate divided the space into east and west two parts. The eastern one is lesser, about $1075 \mathrm{~m}^{2}$, while the western is about $1363 \mathrm{~m}^{2}$

The western one is opposite to the gate of kindergarten. There are three big elms with wooden tree pool benches cutting off the sight line from outside. Those benches are designed to the children standard, which not only can placed teaching items, but also teach them to take a seat in the frontal function, because children are more likely to sit anywhere even on the playground. The most important characteristics of playground is that there are mapped the lovely cartoon design like fish above the green soft plastic to attract children to exercise. At the same time, there are tracks about $20 \mathrm{~m}$ long for children, they can learn some basic sports knowledge and rules. The eastern one is main for physical classes. In the picture(1), kindergarten children with the guidance of teachers are taking physical classes after taking a nap, they are jumping and running, and there are throwing sandbags , which Train their consciousness of cooperation. At about 9:30, the children will be taken to the playground for setting-up exercises during the break. Therefore, in the playground there are some white dots in neat row for children to mark the location of the exercises for children' disorder, so the white dots can teach them about order and rule, and give every child enough space to stretch at the same time.

Publicity space. There are only some simple display boards for propaganda indicating that publicity space is overlooked by kindergarten. Publicity area of BUA kindergarten is located between two playgrounds. Approach trends to be relatively simple. There are only some pictures about children's activities, as well as some excellent works of children. Propaganda of a kindergarten should not be ignored, for it is more a window of aesthetic education in kindergarten than just a propaganda for kindergarten. The meaning of propaganda in "modern Chinese dictionary," is that "explain clearly to people, education, spreading, advocating ", it indicate that propaganda has some meaning of education. So Publicity space should pay more attention to educational elements construction. In a word, foreign propaganda is advertising and promoting kindergarten, the internally should be the transmitting education. This is a shortcoming of BUA kindergarten.

\section{Summary}

According to the construction experience of BUA kindergarten, we should pay attention to the psychological needs of children and the proportion in outdoor environment construction of kindergarten, and value the social attribute of kindergarten. The suggests for each function space are as follows :

1. Education space is necessary for the function attributes of kindergarten. Outdoor education can not only deepen understanding education of morality, intelligence, physique and aesthetic, but also plays an important role for the lack of farmer education, environmental education now days. So the outdoor education space should meets the needs of all kinds of education to have a large enough space and related supporting facilities, and more soft facilities for the environment education. Of course education space must pay attention to the setback education settings. This is a keypoint to their philosophy and value.

2. Games space should be more fancy and originality. Every single child runs average $6 \mathrm{~km}$ every day in a kindergarten designed by Japanese architect Tezuka Takaharu. And in the later a lot of physical 
tests, the kids here scores more than other children every day sit behaving themselves. The reason lies in the uniqueness of game equipment of this kindergarten.

3, Physical activity space may combine distribution and gathering, meanwhile take class size settings into account to ensure existences of both separate space for every class and major places for gathering activities.

4.Experience practice space is a pioneering work in recent years, which connects children and nature. At the same time, it undertake the obligations of the environment education, practice education, and the imagination education for the future, and is important place of free activities and releasing nature. So the space must mix a variety of function, like games, explore, as well as rich natural creatures, in a word, it should be a miniature society.

5. Publicity space is ignored by most of the kindergarten, given the characteristics of children's aesthetic education propaganda, it should be more creative to attract children.

\section{References}

[1]. [1] Ying Xing. Research of the Urban Waterfront Landscape Architecture based on Architecture typology. [D]. Beijing Forestry University, 2011.

[2]. Shi-Yu Pan. The prospect of typology on planning and the application in landscape. [J]. Xiandai Horticulture, 2016, 03:93-94.

[3]. Wen-Mao Zheng. Research on the Urban Street Interface with the Perspective of Typology. [D]. Changan University, 2012.

[4]. Jun-Wei Yang The analysis and application research of typology in urban landscape design [D]. Tongji University, 2008.

[5]. Yue-Yue Yang. The research of landscape based on typology [D]. Hunan Normal University, 2011.

[6]. Zhong Li. The study on diversity of outdoor activities in kindergarten. [D]Sichuan Normal University, 2015

[7]. Wen-ying Zhang. The Typology study on Approaches Of Contemporary Landscape Architecture [J]. Chinese Landscape Architecture, 2008,08:59-68.

[8]. Ting-Hong Guo, Liang Dong. Restoration of Children's Connection with Nature-Therapeutic Garden for Nature-deficit Disorder. [J]. Chinese Landscape Architecture, 2015, 08:62-66.

[9]. Xiao-han Gao. A Preliminary study on outdoor environment of Kindergarten in Beijing [D].Beijing Forestry University, 2007.

[10]. Wei-Hua Shi. A study on outdoor Environment Design of current kindergarten in china with Bejing Haidian District as an example. [D]. Beijing Forestry University, 2011.

[11]. Fang Wang, Cai-Xia Wang. Research on Residential Waterscape Based on Preschoolers and Their Grandparents' Perspectives. [J]. Chinese Landscape Architecture, 2015, 08:67-71.

[12]. Wei Jiang, Ying-Qing Fei, Wen Li. Research the Usage and Space Types of Kindergarten Outdoor_— To Peas Kindergarten as an Example , Guilin [J].Chinese \&Oversea Architecture, 2013,06:62-64. 